\title{
EMergency Medical Services
}

\section{Emergency preparedness: what every health care worker needs to know}

\author{
Michael D. Christian, MD; ${ }^{* \dagger}$ Daniel Kollek, MD; ${ }^{*}+$ Brian Schwartz, MD, FCFP*§
}

\begin{abstract}
Canada is moving forward quickly with plans to ensure that it is prepared to deal with emergencies. The National Framework for Health Emergency Management, released Nov. 26, 2004, recommends that a National Health Incident Management System (IMS) be developed. However, although most communities have successfully implemented IMS in the emergency services sector, many are still struggling with the integration of IMS into their health care systems. It is essential that all health care workers, regardless of profession or position, understand at least the basic concepts of emergency preparedness because of the wide variety of roles they may be asked to fulfill in an emergency situation. This article will review the basic concepts in emergency preparedness and management with a specific focus on IMS in health care.
\end{abstract}

Key words: emergency preparedness; incident management system; incident command system; disaster

\section{RÉSUMÉ}

Le Canada va de l'avant rapidement en élaborant des plans pour assurer qu'il est prêt à faire face aux urgences. Le Cadre national de gestion des situations d'urgence en santé dévoilé le 26 novembre 2004 recommande que l'on établisse un Système national de gestion des incidents en santé (SGI). Même si la plupart des localités ont réussi à mettre sur pied un SGI dans le secteur des services d'urgence, l'intégration du SGI dans leur système de santé pose encore des difficultés à beaucoup d'entre elles. Il est essentiel que tous les travailleurs de la santé, sans égard à leur profession ou à leur poste, comprennent au moins les concepts fondamentaux de la préparation aux interventions en cas d'urgence à cause de la grande variété des rôles qu'on peut leur demander de jouer en situation d'urgence. Dans cet article, on passera en revue les concepts fondamentaux de la préparation et de la prise en charge en cas d'urgence axées spécifiquement sur les SGI en soins de santé.

\section{Background}

Following the September 11th attacks in $2001^{1}$ and the
SARS outbreak in $2003,{ }^{2}$ significant emphasis has been placed on health care emergency preparedness. ${ }^{3-6}$ After first discussing the phases of an emergency, this article will re-

*The Centre for Excellence in Emergency Preparedness, Hamilton, Ont.

tMcMaster University, Faculty of Health Sciences, Department of Medicine, Divisions of Infectious Disease and Critical Care, Hamilton, Ont. ¥McMaster University, Faculty of Health Sciences, Department of Family Medicine, Emergency Medicine Programme, Hamilton, Ont. $\S$ Sunnybrook Osler Centre for Prehospital Care, Sunnybrook and Women's College Health Sciences Centre, Division of Emergency Medicine, Department of Family and Community Medicine, University of Toronto, Toronto, Ont.

Received: Feb. 24, 2005; final submission: July 25, 2005; accepted: July 28, 2005

This article has been peer reviewed.

Can J Emerg Med 2005;7(5):330-7 
view the basic concepts in emergency preparedness and management, including risk assessment, mitigation, preparedness, response and recovery.

Specific attention will be paid to the role of the Incident Management System (IMS), which was identified as a high priority in the National Framework for Health Emergency Management released Nov. 26, 2004. IMS, also known as "Firescope" or Incident Command System, was developed to address difficulties managing California wildfires during the 1970s. ${ }^{8}$ Prior to IMS, multi-agency responses were plagued by inter-agency communication breakdowns, disparate terminology, uncoordinated efforts, lack of response scalability, and ill-defined command structures. IMS has been widely adopted by many North American emergency and disaster response agencies, ${ }^{4,9}$ including most Canadian police, fire and emergency medical services (EMS) first responders. However, while most communities have successfully implemented IMS in their emergency services sector, many have difficulty integrating it into their health care systems.

The key components of IMS are described below, ${ }^{9}$ and the basic structure is outlined in Fig. 1.

- Common terminology: This allows parties from multiple organizations to work together and understand each other.

- Modular organization: Four separate sections (i.e., operations, planning, logistics and finance), along with possible subsections, are developed as needed. This system allows the response to easily be scaled to deal with any size of crisis while maintaining the same basic organizational structure. Fig. 2A, Fig. 2B and Fig. $2 \mathrm{C}$ provide an example of the scalability of IMS.

- Unity of command: A clear chain of command is established whereby each individual within an organization reports to only 1 designated person. Although this chain of command is key to IMS, this "top down" structure is foreign to health care culture and can present a roadblock to implementing this system.

- Unified command structure: Each incident must be coordinated by a sole incident commander regardless of the number of agencies involved in the response. Several agencies or departments can still be represented at the command post and work together to coordinate the response.

- Consolidated Incident Action Plans (IAPs): IAPs are brief written plans, developed by the incident commander or planning chief, defining the response goals, operational objectives and support activities for a specified time period of 8-24 hours. This allows documentation of the decision-making process and facilitates sign-over when there is a change of command.
- Manageable span of control: This defines the number of people who can be effectively managed by 1 person during a crisis and typically ranges between $3-7$ people, with the ideal being 5 .

- Comprehensive resource management: IMS prescribes the manner in which resources are used in an attempt to ensure their use is maximized, the communication load is minimized, accountability is ensured, freelancing is reduced and the safety of the personnel involved is ensured. Based on operational goals response teams are developed, often involving people from different fields working together outside of their traditional organizational structure on a common task.

- Action sheets: These are brief job descriptions created in advance for the common roles in most responses allowing anyone to fill a position. This offers significant flexibility and redundancy should the primary responders, who would typically fill a role, be unavailable for any reason.

\section{Phases of an emergency}

Traditionally, disasters have been conceptualized as having pre-impact, impact, post-impact and recovery phases. ${ }^{10,11}$ The National Framework similarly uses the terms pre-event, event and post-event. ${ }^{7}$ Pre-event activities include risk assessments, mitigation and preparedness. The event may be either static, as a single point in time, or dynamic, evolving over time. Response and recovery occur during the post-event.

\section{Risk assessment}

Two approaches can be used when considering risk. The first is to use an "all-hazards" approach in which a generic plan is devised that is most often designed to deal with a "worstcase" scenario. ${ }^{6}$ When an organization is in the early stages of developing its emergency response capacity, an "all-hazards" approach will ensure that at least a basic and consistent capability to respond exists. Advantages of the "all-hazards" ap-

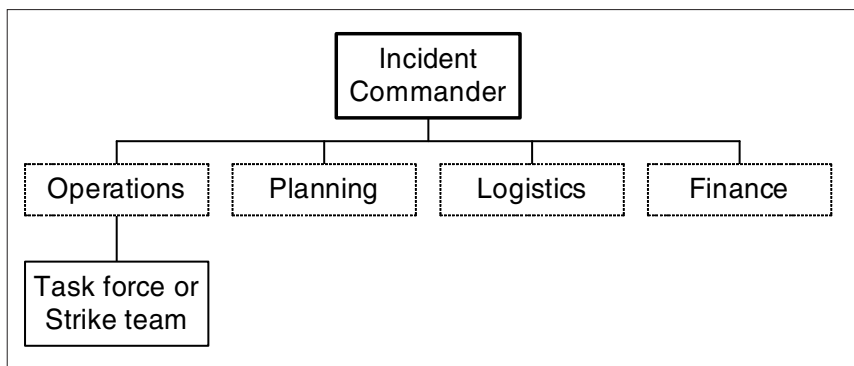

Fig. 1A. Incident Management System (IMS): basic structure At its most basic, the IMS structure consists of an incident commander, who also assumes responsibility for operations, planning and logistics, and a task force or strike team to implement the plan and accomplish the task objectives. 
proach include less time required for planning and being prepared for the unexpected. A significant disadvantage is that it does not allow resources to be targeted to needs nor does it prompt organizations to prepare for unique emergencies such as chemical, biological, radiologic or nuclear events.

Once an organization, such as a hospital, has established a generic all-hazards plan, it can then enhance its capacity by developing hazard-specific plans. Such plans require that a risk assessment be conducted to identify possible hazards, followed by a prioritizing exercise based on their probability and potential impact. High-priority hazards include those that are highly likely to occur, as well as those that are less likely to occur, but would have a devastating impact if they did. Risk assessments should be comprehensive and include both internal and external threats to individual wards or departments and to the facility as a whole. Participants in this process should include representatives from front-line staff, administration, and experts in emergency preparedness. Similar institutions, historical records and individuals with knowledge of the institution's history should be consulted in order to learn from past events. Finally, assessment tools have also been developed to aid health care facilities in conducting their own risk assessments. ${ }^{12}$

The risk assessment process should not be conducted in isolation. Although health care facilities are essentially small communities unto themselves, it is important that they work with the larger community in which they reside. ${ }^{4}$ Community emergency preparedness plans often stop at "patients are transported to hospital," whereas hospital plans begin with "patients arrive from disaster," without consideration of shared risks or integrated planning. External threats to health care facilities can have profound implications ${ }^{13-15}$ that prevent the hospital from fulfilling its mandate, thus jeopardizing the overall community response. ${ }^{16}$ The recent SARS outbreak demonstrated that internal hospital events can have serious consequences for the surrounding community. ${ }^{17}$

\section{Mitigation}

After specific hazards have been identified it may be possible to help mitigate the risk they pose to the health care facility. Mitigation can be through either structural, i.e., building improvements, or non-structural, i.e., policy mea-

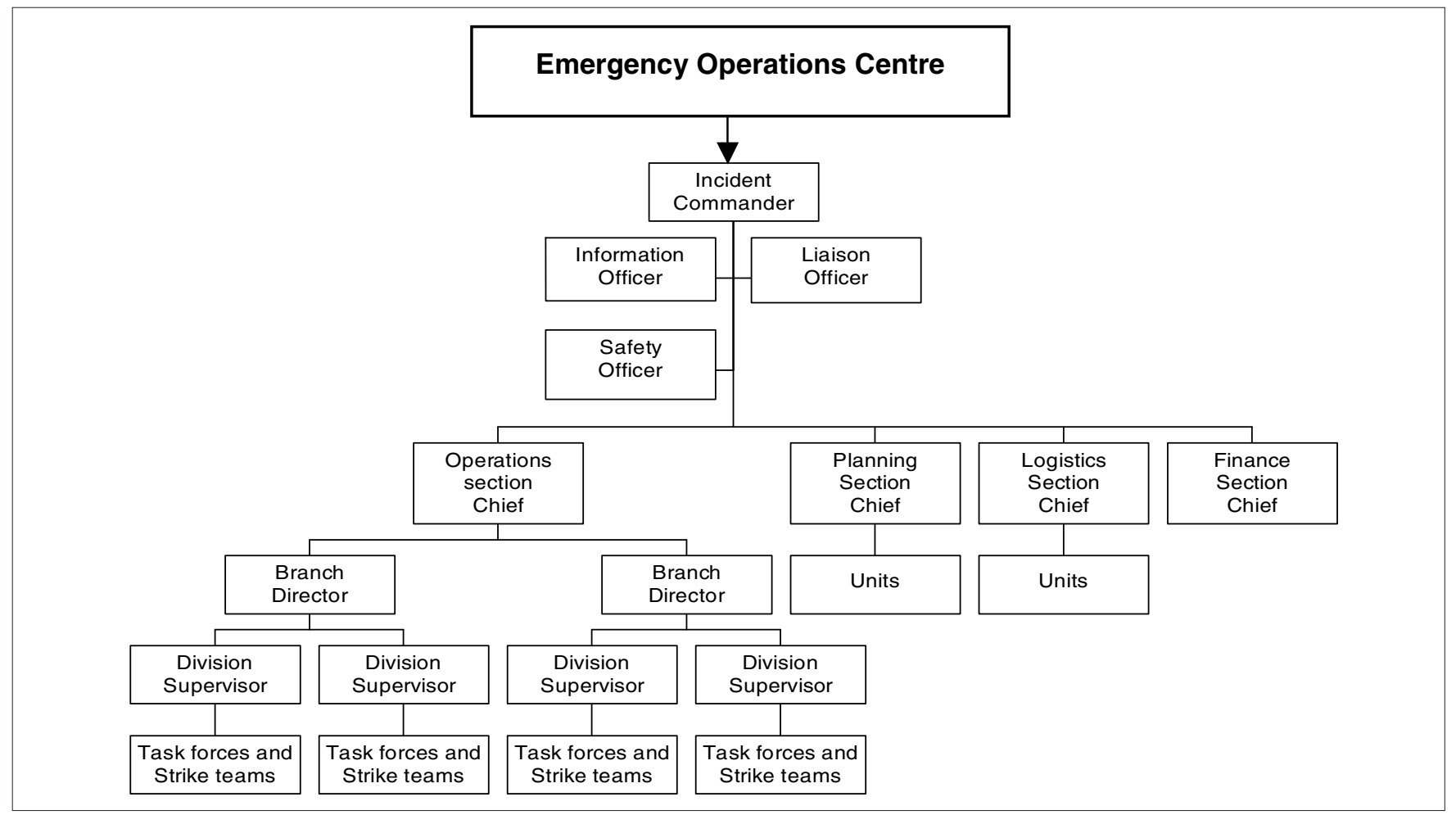

Fig. 1B. The Incident Management System (IMS) fully deployed.

As an incident requires a more complex response, the IMS structure can expand unlimitedly to maintain an appropriate span of control for each supervisor. The information, liaison and safety officers report directly to the incident commander but do not supervise the section chiefs. For complex incidents, an Emergency Operations Centre (EOC) should be organized to support the incident commander, coordinate multiple incidents and interface with other agencies, organizations or levels of government. The EOC is also responsible for maintaining the ongoing function of all other areas of the organization not directly involved in the incident. 
sures. This is the emergency preparedness equivalent to "preventative medicine". Building redundancy into the key systems of the health care facility is one way in which mit- igation can be achieved. Since not all risks can be mitigated, preparedness activities are required to manage an emergency should one occur.

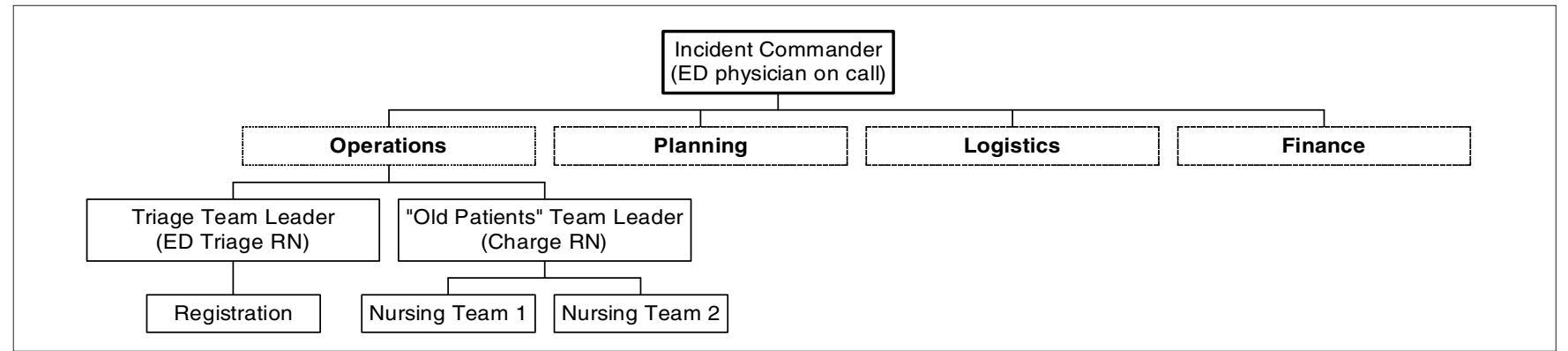

Fig. 2A. Beginning of the incident and activation of IMS.

Walking wounded have just begun to arrive from a chemical explosion. Six patients have arrived at the emergency department (ED) and tell of a major explosion with building collapse. The ED activates its incident command system (IMS) with the ED physician on call assuming the lead for now. He/she also manages the operations/planning/logistic roles until support arrives. The triage nurse starts to triage patients, and the ED charge nurse begins to identify patients who may be suitable for discharge. The ED physician on call asks that both the hospital's chemical response plan be initiated and a Code Orange be declared. Extra support will soon arrive from other staff currently in the hospital and those subsequently being called in. The charge nurse will start to identify patients whose visit is not related to the explosion and who may be ready for discharge. [Note: This is an example of how a hospital might respond to an external disaster. Who and how various IMS roles are fulfilled will vary from event to event and from hospital to hospital.]

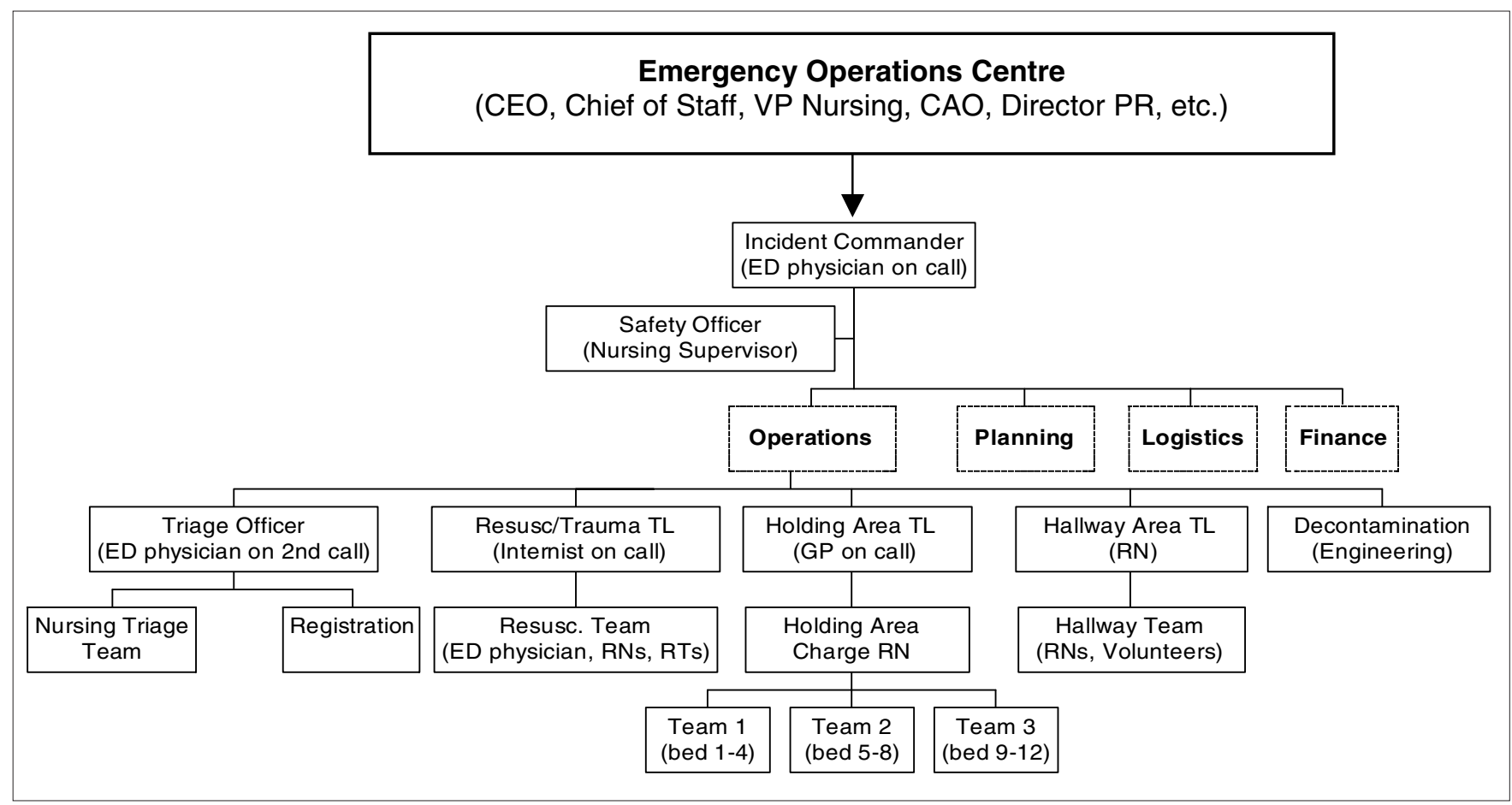

Fig. 2B. Emergency Operations Centre (EOC) opens.

With declaration of a Code Orange the administrators open the EOC to provide support for the incident commander and deal with other operations at the hospital. The EOC begins to lay out its operating cycle. As more staff arrive key roles are filled and resources (i.e., staff) are redeployed to areas as needed. The incident commander continues to oversee operations, planning and logistics for the present time. All other areas (i.e., laboratory, radiology, operating rooms, intensive care unit) have activated their emergency protocols and their own Incident Management System as needed. The surgeon and anesthetist on call will participate in the trauma team, but not lead, because they have to be free to take patients to the operating room. CEO = Chief Executive Officer; VP = Vice President; CAO = Chief Administrative Officer; PR = Public Relations; Resusc. = Resuscitation; $\mathrm{TL}=$ Team Leader; RTs = Respiratory therapists. 


\section{Preparedness}

Preparedness encompasses planning, training, equipping and exercises. Although most, if not all, health care facilities in Canada have a disaster plan, in many cases these plans are not up-to-date ${ }^{18}$ and do not incorporate IMS. Often hospital emergency plans are static documents that are only reviewed every few years before accreditation; they should actually be "living documents" that are reviewed at least every 6 months, and after any internal or external event. Exercises should be done at least once yearly, either in a "table-top" or full-scale format, depending on resources. All staff should receive at least a basic orientation to the plan and IMS.

When IMS is used the emergency plan itself should include the following:

- how the plan is activated and by whom;

- who will be notified upon activation and what information should be provided to them;
- roles and responsibilities for each position;

- members of the Emergency Control Group and who will be responsible for operating the Emergency Operations Centre (EOC);

- criteria for establishment and role of the EOC;

- how the incident commander will be assigned;

- emergency public information plan;

- contingency plans and mutual aid agreements;

- resource lists; and

- who can stand-down the emergency plan.

During emergencies, health care facilities are often reluctant to activate their emergency plan. This can compromise emergency responses; therefore, clear criteria should be included in the plan to describe when and under what circumstances it should be activated. IMS-based emergency plans can even be used for "small" emergencies such as power outages or burst pipes. The full IMS need not be activated

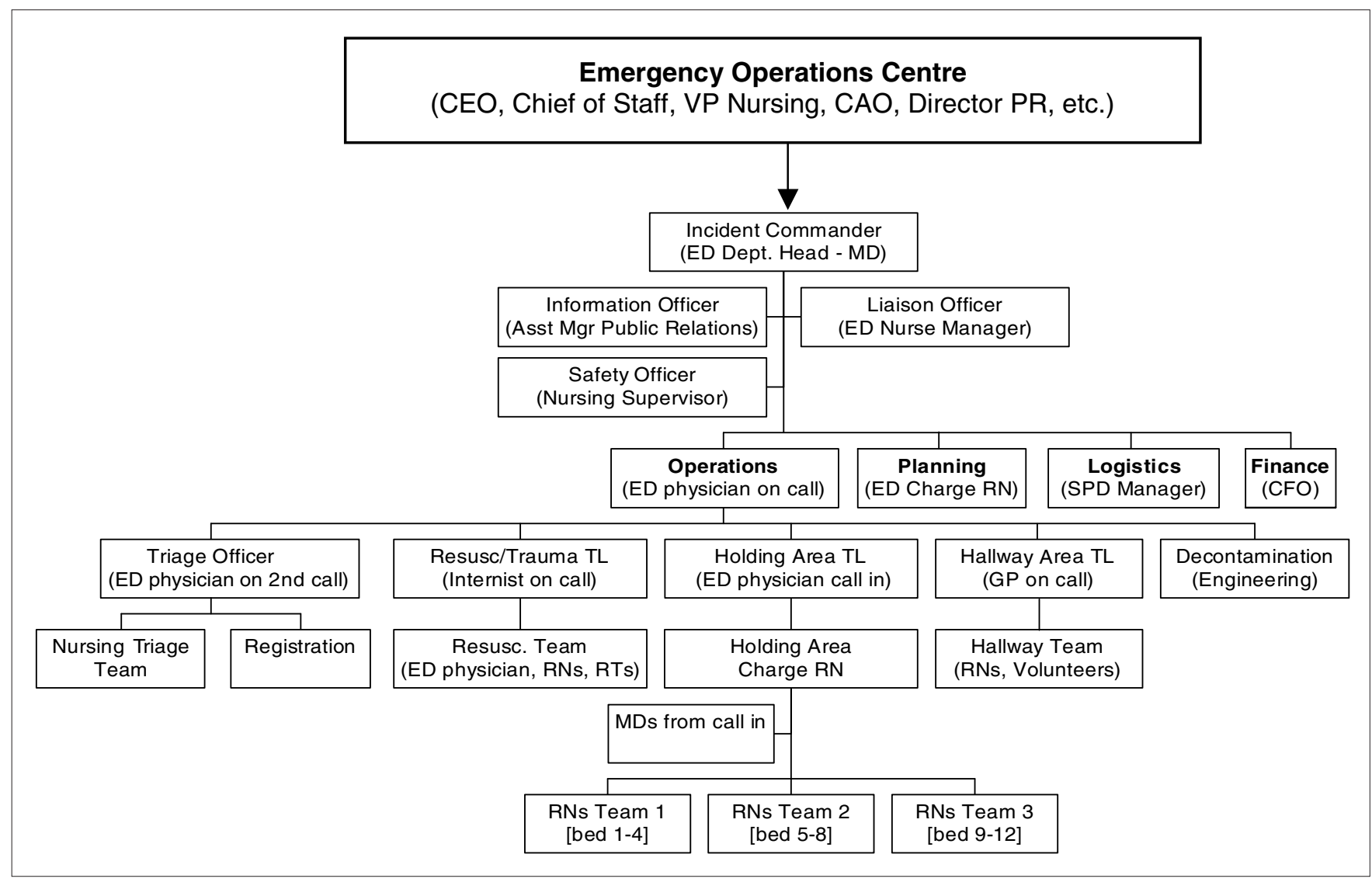

Fig. 2C. Emergency Operations Centre: phase two

Upon the arrival of the head of the emergency department (ED), the ED physician on call takes over operations after briefing the ED department head. As other personnel arrive, the positions of information officer, liaison officer, planning and logistics are staffed. The staff are coping well with large volumes of patients, and there is a clear chain of command with a good flow of communication. The holding area, with fully monitored beds, is acting as an overflow for seriously injured patients until they can be transported to the operating room or intensive care unit or transferred to other hospitals. As the incident enters the recovery phase the structure will begin to contract. $C E O=$ Chief Executive Officer; VP = Vice President; CAO = Chief Administrative Officer; PR = Public Relations; Asst Mgr = Assistant Manager; SPD = Supply, Processing, Distribution; CFO = Chief Financial Officer; Resusc = Resuscitation; $\mathrm{TL}=$ Team Leader; RTs $=$ Respiratory therapists. 
for these, only the components that are relevant. In this way plans can be "exercised" in real time and updated in preparation for more disruptive disaster situations.

Team-work training, although not a traditional component of emergency preparedness, is important given that well-functioning teams are essential for a successful response during an emergency. The aviation industry is a common model that can be used when considering crisis management and response. Airplane crashes are highly visible disasters that share many commonalities with other types of emergencies. A review by the US National Aeronautics and Space Administration following a series of airplane crashes led to the development of the "cockpit resource management" system designed to help prevent future crashes by mitigating causative factors and improving the pilots' ability to respond effectively when problems do arise. ${ }^{19}$ Cockpit resource management includes 4 key components: error identification and management, protocol driven crisis responses, human factors training, and simulator training. Many of these same principles can be applied to help health care facilities prepare for disasters and improve health care workers' capacity to respond. Furthermore, the cockpit resource management system may have a secondary benefit of reducing medical errors. ${ }^{19-25}$

\section{Response}

Effective emergency responses are well controlled and coordinated. This necessitates the use of a response strategy such as IMS, which has proven its utility through use in a wide variety of incidents (Table 1).

A key factor that has led to the success of IMS is that it can be used for responses of any size. For instance, most fire departments use IMS on every call regardless of whether it is a single motor vehicle collision or a major structural fire. For smaller incidents a written incident action plan is not required and the incident commander can assume all of the primary management roles, still allowing for the scale of the response to be expanded if required.

Table 1. Past uses of the Incident Management System

- HAZMAT and terrorist incidents

- Mass gatherings (e.g., celebrations, parades, concerts, official visits)

- Natural hazards and fires

- Incidents involving multiple casualties

- Multi-jurisdictional and multi-agency incidents

- $\quad$ Air, rail, water or ground transportation accidents

- Wide-area search-and-rescue missions

- Pest eradication programs

- $\quad$ Private-sector emergency management programs.
Incident command is assigned to the person best suited to manage the specific type of incident. Major incidents should prompt the development of an EOC where the Emergency Control Group, led by the chief executive officer (CEO), will support the incident commander, coordinate responses if multiple incidents are involved, and maintain all other operations of the organization that are not directly related to the incident. Each incident should be defined by a single geographic location or other characteristic, and should have its own commander.

A benefit of IMS is that it incorporates often overlooked actions such as the documentation of financial costs and decision-making processes. Moreover, the collection of the information required to plan and document the incident also readily facilitates incorporating a parallel research arm in the IMS (Fig. 3). Such research can help to improve future responses or produce "real-time" data for modifying the current response. An example would be an outbreak of a novel infectious agent where clinical trials are conducted as the outbreak evolves. These trials could help to define what treatments are effective.

The Hospital Emergency Incident Command (HEICS) was developed to facilitate the uptake of IMS by health organizations. ${ }^{4,6,26}$ HEICS is a substantially modified version of IMS that more closely resembles hospital organizational structure. While this makes it easier for health care administrators to identify with, it reduces the flexibility of the system, fails to encourage an objective-driven response, and relies upon specific people to fill specific roles, thus leaving the response vulnerable if these people are unavailable. Further, organizational discrepancies between HEICS and traditional IMS can impede communication between outside agencies and the hospital, one of the key issues IMS was developed to address. Canadian hospitals that have adopted HEICS may find it prudent to shift to a more traditional IMS model in order to maintain consistency with emergency services and other organizations that have followed the National Framework and have adopted a traditional IMS model. ${ }^{7}$

\section{Recovery}

The transition from response to recovery is graded and in many cases both actions occur simultaneously. The speed with which an organization can return to normal functioning is an indicator of the organization's overall ability to manage an emergency. Given the importance of the health care system to the overall community, it is essential that the health care organization not only have a response plan but also an operational, or business, continuity plan. Just as the response plan identifies a team to deal with an event, it should also identify a team to coordinate the recovery. The 
Emergency Control Group, led by the CEO, oversees both the response and recovery activities. In many instances the recovery activities will be shaped by the lessons learned from the disaster and thus lead full circle to mitigation actions to prevent a similar situation in the future.

\section{Discussion}

\section{Barriers to IMS in health care settings}

The authors of this paper have consulted on IMS development and implementation at various levels, from the federal framework down to local hospitals. As consultants, we have observed 3 recurrent issues that impede IMS implementation in health care settings. The first is that IMS has largely been used in the public sector for emergency first responders such as police, fire and EMS. Traditionally hospitals have not been considered as first responders but as resources. However, hospitals are, in fact, first responders albeit "non-mobile first responders" or, more accurately, hospitals are "first receivers," as is clearly evident by both the September 11th attacks and the sarin gas attacks in Japan. ${ }^{27-29}$ Dividing first responders into "mobile" and "non-mobile" responders facilitates understanding of how IMS applies to hospitals. Second, although "team-building" is a mantra heard throughout Canadian health care, there are few formal activities aimed at promoting team work, and these skills are essential for an effective IMS re- sponse. Finally, much of the past 3 decades has been spent breaking down the hierarchical medical system in attempts to develop a collaborative model. ${ }^{30}$ Ironically, a hierarchical "command and control" structure, such as that seen in IMS, is essential for an effective response to a crisis. This type of approach has become foreign to many in health care, and can lead to resistance to using IMS, whereas most other organizations using IMS such as police, fire, EMS and even the private sector have paramilitary or "topdown" organizational structures respectively.

\section{Conclusion}

The Canadian health care system is moving quickly to ensure that it is prepared to deal with emergencies. Many concepts in the proposed emergency management framework, particularly the IMS, will be unfamiliar to health care workers. Disaster may strike any time and health care workers, especially emergency department staff, will be called upon to collaborate with community response agencies and coordinate the critical in-hospital response; therefore, it is essential that they are familiar with the concepts described in this article.

Acknowledgement: We thank Paul Moir for assistance with graphic design.

Competing interests: None declared.

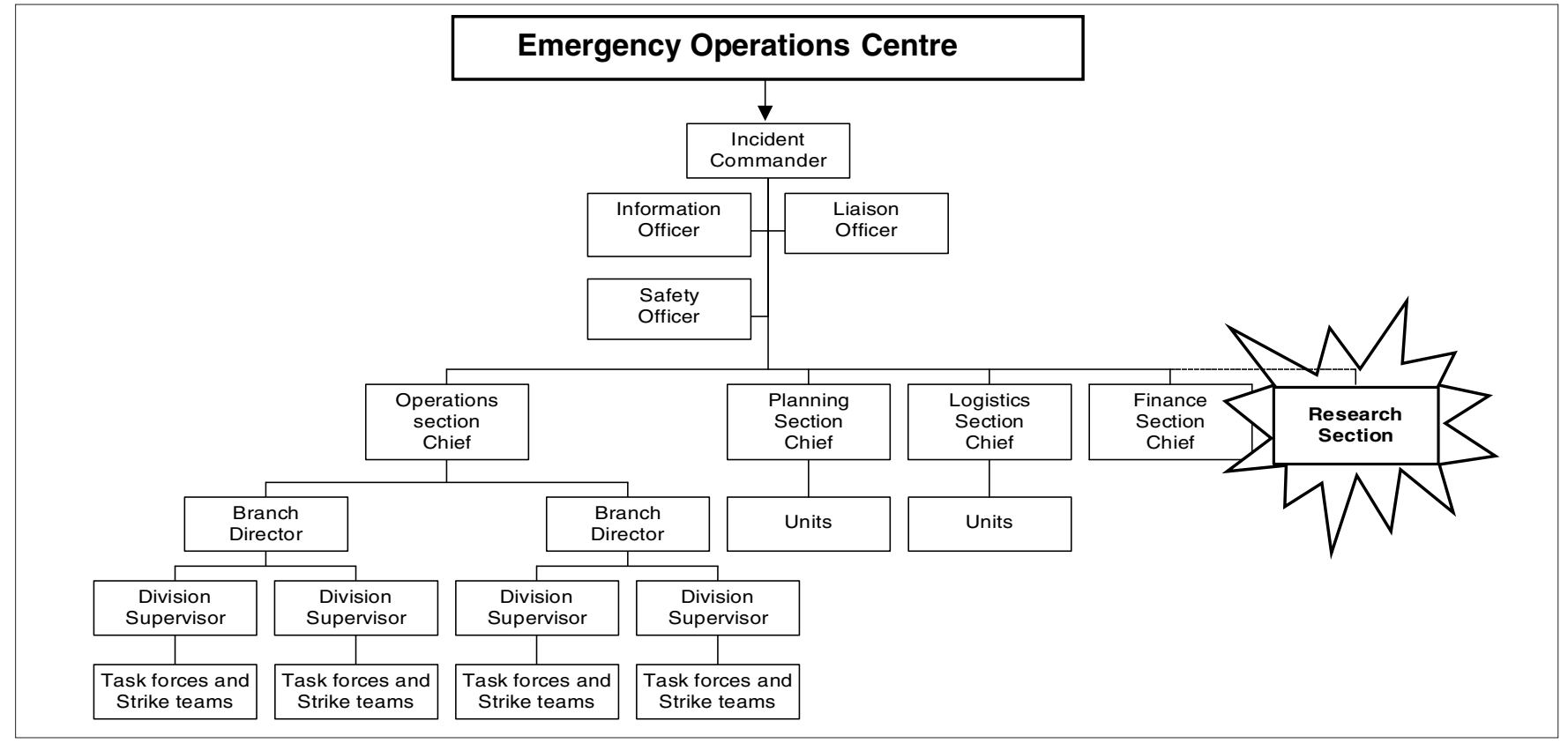

Fig. 3. Emergency Operations Centre: research section.

The addition of a research section would allow improvements in responses to future incidents. In addition, there is also the possibility of developing "real-time data" through the research that may help to inform the operations and planning sections of the incident as it develops. 


\section{References}

1. Nuttall S, Tyler S. The crisis of September 11: the emergency response of Ontario hospitals and other health system partners. Hosp Q 2001;5:42-50.

2. Christian MD, Poutanen SM, Loutfy MR, Muller MP, Low DE. Severe acute respiratory syndrome. Clin Infect Dis 2004;38:1420-7.

3. A Canadian agency for public health: if not now, when? [editorial]. CMAJ 2003;169(8):741.

4. Berman MA, Lazar EJ. Hospital emergency preparedness lessons learned since Northridge. N Engl J Med 2003;348:1307-8.

5. Bevan D. SARS 3: Are we ready? [editorial]. Clin Invest Med 2003;26:273-4.

6. Schultz CH, Mothershead JL, Field M. Bioterrorism preparedness. I: The emergency department and hospital. Emerg Med Clin North Am 2002;20:437-55.

7. Federal/Provincial/Territorial Network on Emergency Preparedness and Response. National Framework for Health Emergency Management.

8. Christen H, Maniscalco P, Vickery A, Winslow F. An overview of incident management systems. Perspectives on Preparedness Series. Belfer Center for Science and International Affairs, Harvard University; 2001. Available: www.innovations.harvard .edu/showdoc.html?id=4915 (accessed 2005 Aug 5).

9. US Federal Emergency Management Agency (FEMA). National Incident Management System Training Manual. 2004. Available: www.fema.gov/nims/nims_training.shtm (accessed 2005 Aug 9).

10. Aghababian RV, Teuscher J. Infectious diseases following major disasters. Ann Emerg Med 1992;21:362-7.

11. Binder S, Sanderson LM. The role of the epidemiologist in natural disasters. Ann Emerg Med 1987;16:1081-4.

12. Public Health Preparedness and Response Capacity Inventory. US Centers for Disease Control and Prevention, Public Health Practice Program Office (PHPPO). 2004. Available: www.bt.cdc.gov/planning/ (accessed 2005 Aug 16 ).

13. Freedman TJ, Gerring G. Blackout! Are you prepared? Leadersh Health Serv 1992;1:22-6.

14. Henry S. Mississauga Hospital: largest evacuation in Canada's history. CMAJ 1980;122:582-6.

15. Schultz CH, Koenig KL, Lewis RJ. Implications of hospital evacuation after the Northridge, California, earthquake. N Engl J Med 2003;348:1349-55.

16. Socha A, Abernethy S, Birmingham B, Bloxam R, Fleming S, et al; for the Ontario Ministry of Environment and Energy. Plastimet Fire Inc., Hamilton, Ont., July 9-12, 1997. 1997 Oct. Available: www.ene.gov.on.ca/envision/techdocs/3598e.pdf (accessed 2005 Aug 16).

17. Wallington T, Berger L, Henry B, Shahin R, Yaffe B, Mederski $\mathrm{B}$, et al. Update: severe acute respiratory syndrome - Toronto, 2003. Can Commun Dis Rep 2003;29:113-7.

18. Kollek D. Canadian emergency department preparedness for a nuclear, biological or chemical event. Can J Emerg Med 2003;5(1):18-26.

19. Helmreich RL. On error management: lessons from aviation. BMJ 2000;320:781-5.

20. Gaba DM. Anaesthesiology as a model for patient safety in health care. BMJ 2000;320:785-8.

21. Hugh TB. New strategies to prevent laparoscopic bile duct injury - surgeons can learn from pilots. Surgery 2002;132:826-35.

22. Marsch SC, Muller C, Marquardt K, Conrad G, Tschan F, Hunziker PR. Human factors affect the quality of cardiopulmonary resuscitation in simulated cardiac arrests. Resuscitation 2004;60:51-6.

23. Morey JC, Simon R, Jay GD, Wears RL, Salisbury M, Dukes $\mathrm{KA}$, et al. Error reduction and performance improvement in the emergency department through formal teamwork training: evaluation results of the MedTeams project. Health Serv Res 2002;37:1553-81.

24. Nolan TW. System changes to improve patient safety. BMJ 2000;320:771-3

25. Shirely PJ. Reducing error, improving safety. Crew resource management training should be mandatory in anaesthesia [letter]. BMJ 2000;321:508-9.

26. San Mateo County Emergency Medical Services Agency. HEICS III. Hospital Emergency Incident Command System. 2004. Available: www.emsa.ca.gov/Dms2/heics3.htm (accessed 2005 Aug 9).

27. Aubrey L. The hard lessons of September. Mod Healthc 2002;32:50.

28. Cushman JG, Pachter HL, Beaton HL. Two New York City hospitals' surgical response to the September 11, 2001, terrorist attack in New York City. J Trauma 2003;54:147-54.

29. Okudera H, Morita H, Iwashita T, Shibata T, Otagiri T, Kobayashi S, et al. Unexpected nerve gas exposure in the city of Matsumoto: report of rescue activity in the first sarin gas terrorism. Am J Emerg Med 1997; 15:527-8.

30. Hojat M, Nasca TJ, Cohen MJ, Fields SK, Rattner SL, Griffiths $\mathrm{M}$, et al. Attitudes toward physician-nurse collaboration: a cross-cultural study of male and female physicians and nurses in the United States and Mexico. Nurs Res 2001;50:123-8.

Correspondence to: Dr. Michael D. Christian, Hamilton General Hospital, McMaster Wing, Rm. 627, 237 Barton St E, Hamilton ON L8L 2X2

\section{Resources}

For those interested in learning more about emergency preparedness we suggest these Web pages and documents:

\section{www.ceep.ca}

- The Canadian Centre For Excellence in Emergency Preparedness. This Web site includes information and links for a broad range of information related to emergency preparedness for those in health care.

www.bt.cdc.gov

- The emergency preparedness and response Web site for the US Centers for Disease Control and Prevention. This site contains information regarding chemical, biological, radiation and nuclear emergencies. It also includes material on training.

\section{www.nfpa.org}

- The National Fire Protection Association, which publishes the Standard on Disaster/Emergency Management and Business Continuity (NFPA 1600). This is the basis for the incident management system.

www.fema.gov

- The US Federal Emergency Management Agency. An excellent source of online training material and courses. 